\title{
Obrazowanie sportu i rekreacji ruchowej w fabułach zabaw dydaktycznych
}

\section{Depiction of sport and physical recreation in the storylines of didactic games}

This text is an extract from an extensive study into conveying culture through the storylines of didactic games. The presented material focuses on the issue of sport and physical recreation in its broader sense.

In the report the results of the study have been presented, which included the storylines of 851 artistic activities and 851 musical and physical activities. To that end, textbooks intended for teachers have been referred to. Both kinds of games are being used while working with pupils of different ages in kindergartens and schools.

In the study a set of several methods were used to reconstruct the transmission of didactic games. The storyline of each game was assessed as a whole on the basis of the modified technique of a case study. By this means a description of the world aimed at pupils has been provided.

As shown, in the storylines of didactic games practically no themes of sport appear. Moreover, the physical recreation was relatively rarely presented to the pupils. That implies that the employment of the assessed games as a form of physical exertion promotion was not intended. Summing up, the study of methodical solutions overcoming the discussed problem has been suggested.

\section{Wprowadzenie}

W 1907 roku Kazimierz Hemerling wyraził przekonanie, że zabawa w czasach przedhistorycznych była poprzedniczką kultury ułatwiającą krystalizowanie się tożsamości populacji. Tezę tę trzydzieści lat później powtórzył i spopularyzował Johannes Huizinga, któremu czasem mylnie przypisuje się jej autorstwo (Hemerling, 1907, Huizinga, 1938 [1985]). 
Trudno dziś stwierdzić, czy pogląd ten jest trafny, brakuje wszakże dowodów, które mogłyby o tym rozstrzygnąć. Niewątpliwie jednak gry i zabawy od dawna z powodzeniem wykorzystywano w nauczaniu i wychowywaniu dzieci. Zapewne dlatego już dwieście pięćdziesiąt lat temu stosowano je w polskich szkołach (Wroczyński, 1985). Warto odnotować i to, że pierwszy polskojęzyczny zbiór zabaw pochodzi z 1821, a kolejne ukazywały się systematycznie w następnych dziesięcioleciach (Zbiór rozmaitych zabaw..., 1821, Gołębiowski, 1831, Kozłowski, 1869).

Także współcześnie, w zajęciach dla wychowanków przedszkoli i uczniów pierwszych trzech klas szkół podstawowych, korzysta się głównie z zabaw dydaktycznych, a nie zadań w formach ścisłych (Nowak-Łojewska, 2004; Waloszek, Hammerling, 1985). Analogiczne rozwiązanie przyjmuje się także w innych krajach (Bunker, Gallahue, Cleland-Donnelly, 2007, Lenel, 1984, Walter, 1999, Corbin, Lindsey, 1997). Podkreśla się przy tym, że poprzez fabuły takich zabaw można kształtować postawy i kompetencje społeczne dzieci oraz wyznawane przez nie wartości (Bizley, 1996, Winczewski, 2014a). Wychowankowie, inscenizując zachowania bohaterów fabuł, niejako „przy okazji” ugruntowują wiedzę o świecie oraz doświadczają możliwości jej praktycznego zastosowania (Kist, 2011, Boyarsky, 2011, Więckowski, 1998). Poprzez takie zabawy ułatwia się ponadto kilkulatkom nauczenie się tego, jak skutecznie można radzić sobie z wyzwaniami (Potter, 2004, Beith, Robinson, Pullan, 2003). W ten sposób socjalizuje się dzieci wprowadzając je w świat kultury.

Zadanie scalania oddziaływań wdrażających uczniów do systematycznej aktywności ruchowej spoczywa na szkolnym koordynatorze wychowania zdrowotnego - nauczycielu wychowania fizycznego (Woynarowska, 2012). Dlatego jego szczególną powinnością jest zadbanie o to, aby powiązane z nią treści rzeczywiście pojawiały się w trakcie lekcji licznych przedmiotów szkolnych, w tym zajęć plastyki i muzyki. Z tego względu postanowiono ocenić treści zabaw wspomnianych rodzajów, by oszacować rozmiar wyzwań, przed którymi staje nauczyciel wychowania fizycznego.

\section{Założenia}

W związku z powyższym przyjęto, że na podstawie analizy opisów świata kolportowanych przez fabuły, narracje i didaskalia zabaw można odczytać kierowany do ucznia przekaz wychowawczy i dydaktyczny. Podobnie określiła horyzont metodologiczny swych rozważań Aldona Molesztak. Konweniuje on z orientacją metodologiczną opisaną przez Bogusławę Matwijów. Zgodnie z ujęciem tych autorek, zabawy dydaktyczne można traktować jako formę transmitowania kultury kolejnym pokoleniom (Molesztak, 1994, Matwijów, 1998).

W nawiązaniu do tych stanowisk, w prezentowanych badaniach przyjęto założenie, że kilkulatek może uważać, że treści obrazowane przez fabuły, narracje i didaskalia zabaw dydaktycznych ukazują mu właściwy sposób rozumienia świata, w tym pożądane zachowania sportowe i rekreacyjne. 


\section{Cel badań}

Opisywane poniżej badania są wycinkiem szerszych rozważań nad formami transmitowania treści kultury z wykorzystaniem zabaw dydaktycznych. Podczas nich planowano ocenić, jak wykorzystuje się fabuły zabaw plastycznych i muzyczno-ruchowych do opisywania kilkuletnim wychowankom szeroko rozumianego sportu oraz rekreacji ruchowej. W ten sposób zamierzano uzyskać obraz jednego z aspektów wychowania dzieci do uczestniczenia w kulturze fizycznej.

Eksploracji nadano charakter badań stosowanych (Cuttance, 1996, Pilch, Bauman, 2001). Wnioski z niej mogą bowiem mieć (choćby potencjalnie) wpływ na rzeczywistą praktykę szkolną. Ujawnienie rzeczywistego przekazu zabaw może bowiem skłonić do refleksji nad zasadami ich selekcjonowania na etapie planowania zajęć (Reid, Hopkins, Holly, 1990, Palka, 2006, Gnitecki, 1996b). Taką procedurę badawczą nazywa się w pedagogice aplikacyjną (teoretyczno-praktyczną) (Palka, 2006) lub eksploracyjno-diagnostyczną (Żechowska, 1985).

\section{Materiał badawczy}

W badaniach wykorzystano opisy 851 zabaw muzyczno-ruchowych i tyle samo plastycznych. Zaczerpnięto je ze współczesnych polskojęzycznych podręczników metodycznych adresowanych do nauczycieli prowadzących zajęcia w przedszkolach i szkołach podstawowych.

Materiał wyselekcjonowano losowo spośród bogatej twórczości metodycznej. Dobór próby miał przy tym charakter gronowy (Góralski, 1987). Rekrutując zabawy do oceny tak dobierano podręczniki, by liczby zawartych w nich zabaw obu kategorii okazały się ostatecznie identyczne. Miało to z jednej strony zapewnić losowy dobór próby, $z$ drugiej zaś ułatwić sprowadzanie wniosków do wspólnego mianownika (wysnucie ich z porównywalnego materiału). Wskutek powyższego oceniono zawartość siedmiu książek zawierających zabawy muzyczno-ruchowe oraz 14 podręczników prezentujących zabawy plastyczne.

\section{Metody i techniki}

Analizę treści fabuł zabaw dydaktycznych przeprowadzono z wykorzystaniem kilku metod. Poszczególne z nich zastosowano w kolejnych częściach badań. Tak postępują także inni autorzy prowadzący eksploracje o charakterze jakościowym (Schutz, Chambless, DeCuir, 2008).

Początkowy etap badań oparto na rekonstrukcji logicznej, która jest szczególnie odpowiednia w rozważaniach o charakterze ex post facto. Prowadząc dociekania o takim charakterze dąży się bowiem do wykrycia i opisania zjawiska poddanego analizie (Żechowska, 1985, Spencer, Ritchie, Lewis, Dillon, 2003, 
Kmita, 1971). Zwyczajowo przeprowadzony zabieg uważa się za jedną z postaci hermeneutyki obiektywnej (Urbaniak-Zając, 2013). W badaniach prowadzonych z jej wykorzystaniem pedagodzy koncentrują uwagę na treściach transmitowanego przekazu kulturowego (Gnitecki, 1996a).

W związku z powyższym opisy dydaktycznych zabaw traktowano jako dokumenty („obiekty kultury”, „znaki”), a interpretowaniu poddano ich „oznaki humanistyczne". Odkodowywanie treści: narracji, fabuł i didaskaliów tych zabaw stanowiło wobec tego „czynność kulturową" objaśniającą ich „sens kulturowy” (Silverman, 2007, De Vaus, 1996, Kmita, 1971).

Treść fabuł i didaskaliów ocenianych zabaw dydaktycznych przeanalizowano, korzystając z przekształconej techniki studium przypadku po zaadaptowaniu jej do wymogów metodologicznych hermeneutyki obiektywnej (McNeill, 1986, Urbaniak-Zając, 2013, Pilch, Bauman, 2001). Syntetycznymi studiami objęto zatem nie osoby, ale teksty (Urbaniak-Zając, 2013). Pojedynczy opis zabawy przyjmowano wobec tego za reprezentanta ujawnianej prawidłowości (Macdonald, Tipton, 1996). Zgromadzone dane ewidencjonowano w standaryzowanych arkuszach obserwacyjnych (Bell, 1995; McNeill, 1986, Łobocki, 2003; Pieter, 1967).

Po syntetycznym zinterpretowaniu każdej z zabaw efekty tego zabiegu opisano, wykorzystując elementarną statystykę. W ten sposób scalono metody i techniki jakościowe z ilościowymi. Takie rozwiązania przyjmują także inni autorzy (Leech, Onwuegbuzie, 2009, Goodwin, Goodwin, 1996, Pilch, Bauman, 2001).

\section{Pytania badawcze}

Jak oceniono, w oparciu o przegląd opracowań z zakresu pedagogiki zabawy, zastosowany schemat badań nad fabułami zabaw dotychczas nie pojawił się w publikacjach innych autorów. Wskutek tego nie można było postawić hipotez korespondujących z wcześniejszymi doniesieniami. To relatywnie częsta sytuacja w eksploracjach o charakterze jakościowym (Flick, 2011). W efekcie tego zrezygnowano z przyjmowania hipotez, stawiając jedynie pytania badawcze.

Podczas eksploracji zamierzano ujawnić zawarte w zabawach (podręcznikach) opisy i wizualizacje: strojów sportowych, nazw dyscyplin i konkurencji sportowych oraz form rekreacji ruchowej, ceremoniału olimpijskiego, a także ludzi sportu (zawodników, trenerów, sędziów, komentatorów, kibiców). W związku z tym poszukiwano odpowiedzi na poniższe pytania badawcze:

1. Jak wiele rodzajów strojów sportowych opisano w fabułach ocenianych zabaw?

2. Jak wiele fabuł zabaw ilustruje dyscypliny i konkurencje sportowe oraz formy rekreacji ruchowej?

3. Jak często w zabawach pojawia się obrazowanie ceremoniału olimpijskiego?

4. Jak często w zabawach obrazuje się ludzi sportu (zawodników, trenerów, sędziów, komentatorów, kibiców i innych współtworzących atmosferę rywalizacji)? 


\section{Wskaźniki}

Podczas udzielania odpowiedzi na pytania badawcze oszacowywano częstość prezentowania w materiale badawczym oznak, indeksów i symptomów (Kmita, 1971): strojów sportowych, nazw dyscyplin i konkurencji sportowych oraz form rekreacji ruchowej, ceremoniału olimpijskiego, a także ludzi sportu (zawodników, trenerów, sędziów, komentatorów, kibiców).

\section{Prezentacja wyników badań}

\section{Próba odpowiedzi na pytanie 1}

W ledwie jednej zabawie plastycznej ilustrowano strój sportowy - kombinezon narciarski. Raz pojawił się ponadto motyw torby na lekcje tańca. W zabawach muzyczno-ruchowych nie opisano żadnego stroju sportowego lub służącego rekreacji ruchowej.

W efekcie tego stwierdzono, że ocenione zabawy nie prezentują ani ubiorów sportowych, ani strojów rekreacyjnych. Oznacza to, że kilkulatkom, poprzez ocenione zabawy, nie przekazywano za pośrednictwem ilustracji tego, że intensywna aktywność sportowo-rekreacyjna wymaga stosowania specjalistycznej odzieży.

\section{Próba odpowiedzi na pytanie 2}

W zabawach muzyczno-ruchowych odnotowano następujące formy sportu i rekreacji ruchowej (ćwiczeń): rzucanie - podrzucanie piłki (20 razy), używanie sanek (pięciokrotnie), korzystanie z roweru (cztery razy), podrzucanie woreczka gimnastycznego (trzykrotnie), jeżdżenie na łyżwach (dwa razy), gimnastykę i rzuty patyczkiem, używanie skakanki, boksowanie, skoki spadochronowe, żeglowanie, zjeżdżanie na nartach oraz grę w piłkę nożną (po razie).

Warto przy tym podkreślić, iż ledwie po razie dookreślono, że opisano piłkę ping-pongową oraz nożną. Pozostałych piłek bliżej nie scharakteryzowano.

W zabawach plastycznych, spośród dyscyplin i konkurencji sportowych oraz form rekreacji i ćwiczeń ruchowych, przedstawiono jedynie: wędkowanie (trzykrotnie), narciarstwo i puszczanie latawca (po dwa razy), taniec, grę w szachy, wiosłowanie, grę w kręgle, spadochroniarstwo, zabawy na sankach (po razie).

Jak zatem zauważamy, w obu rodzajach zabaw nieomal zupełnie przemilczano istnienie sportu wyczynowego. W ich fabułach pojawiły się praktycznie jedynie formy rekreacji ruchowej. Motywy te obrazowano w co około dwudziestej zabawie muzyczno-ruchowej (4,9\% z nich) i raz na około 66 zabaw plastycznych. 


\section{Próba odpowiedzi na pytanie 3}

W żadnej z ocenianych zabaw nie nawiązywano do ceremoniału olimpijskiego. W związku z tym należy uznać, że nie propagują one idei olimpizmu.

\section{Próba odpowiedzi na pytanie 4}

W trzech zabawach muzyczno-ruchowych opisano postacie sportu: wymienionego z nazwiska piłkarza nożnego, żeglarza oraz narciarza. W zabawach plastycznych wymieniono: trzy razy wędkarza i po razie: narciarza, wioślarza oraz spadochroniarza.

W związku z powyższym uznano, że w fabułach ocenionych zabaw praktycznie nie opisuje się zawodników ani innych postaci sportu. Motyw ten można zatem uznać za zmarginalizowany.

\section{Podsumowanie i dyskusja}

Należy zauważyć, że w szkole podstawowej rocznie prowadzi się co najwyżej czterdzieści lekcji plastyki i tyle samo muzyki. W związku z powyższym uznano, że oceniony materiał ani nie opisuje wychowankom miejsc odbywania się rywalizacji sportowej, ani służących rekreacji ruchowej. Motywy te bowiem pojawiały się rzadziej niż raz na sto zabaw plastycznych (ściślej: w 0,7\% z nich) i w 0,59\% zabaw muzyczno-ruchowych. Oznacza to nawiązywanie do tej tematyki, w trakcie lekcji plastyki i muzyki, rzadziej niż raz na trzy lata.

Warto zauważyć, że aktywność sportowa i rekreacyjna pojawiają się w fabułach zabaw dydaktycznych zdecydowanie rzadziej niż wiele innych motywów. W zabawach muzyczno-ruchowych częściej obrazuje się między innymi: faunę (27,92\% fabuł), florę $(24,51 \%)$, naturę nieożywioną $(20,29 \%)$, detale architektoniczne i budynki $(16,40 \%)$, zawody $(10,88 \%)$, przyrządy i urządzenia $(9,90 \%)$, pojazdy $(9,01 \%)$, a także niebezpieczeństwa i zagrożenia $(8,44 \%)$, relacje wewnątrzrodzinne $(5,52 \%)$ i instrumenty muzyczne $(4,63 \%)$ (Winczewski, 2014a, s. 53-67). Z kolei w zabawach plastycznych częściej od motywów sportu i rekreacji ruchowej pojawiały się między innymi: fauna (26,6\% fabuł), postaci $(15,29 \%)$, przedmioty użytkowe i zabawki $(14,68 \%)$, flora $(11,85 \%)$, fantastyka, motywy mitologiczne i religijne $(7,27 \%)$, natura nieożywiona $(6,26 \%)$ (inny fragment niniejszych badań oczekujący na opublikowanie).

Równocześnie treści zabaw ruchowych obrazują mnogie motywy wykraczające poza zagadnienia typowe dla wf. Zagrożenia obrazuje się w $12,02 \%$ z nich, faunę w 8,74\%, aktywność zawodową w 3,65\%, przyrodę nieożywioną w 2,09\% $z$ nich, urządzenia w $1,91 \%$, florę $w 1,56 \%$, przedstawicieli innych nacji w $1,28 \%$, zjawisko niepełnosprawności w 1,13\% (Winczewski, 2015). W związku z tym 
należałoby oczekiwać, że aktywność sportowa i rekreacyjna także stanie się tematem innych rodzajów zabaw, w tym plastycznych i muzycznych. Tak jednak, jak wykazano wyżej, nie jest.

\section{Konkluzja}

W zgodzie z powyższym uznajemy za pożądane opracowanie zabaw plastycznych i muzycznych obrazujących kilkulatkom liczne przejawy sportu i rekreacji ruchowej. Może to przybliżyć te zagadnienia w podręcznikach metodycznych adresowanych do nauczycieli muzyki i plastyki. Okazało się bowiem, że dotychczas tematyka ta nie pojawia się w fabułach zawartych w nich zabaw. Zaproponowane rozwiązanie może stanowić sugestię do podjęcia tematu wysiłków sportowo-rekreacyjnych w pracy z wychowankami przedszkoli i uczniami szkół podstawowych.

\section{Wnioski}

1. W analizowanym materiale praktycznie nie odnotowano istnienia sportu wyczynowego. W fabułach zabaw nie prezentowano ani strojów wykorzystywanych przez wyczynowców, ani poszczególnych konkurencji, dyscyplin sportu czy też postaci sportu. Nieobecne były też aspekty ceremoniału olimpijskiego.

2. Jak stwierdzono, wielorakie przejawy sportu praktycznie nie pojawiają się w fabułach zabaw plastycznych i muzyczno-ruchowych. W związku z tym uznano, że tematyka ta nie jest w zorganizowany i konsekwentny sposób prezentowana uczniom i wychowankom przedszkoli.

3. Równocześnie jednak $w$ fabułach ocenianych zabaw pojawiły się pewne formy rekreacji i ćwiczeń ruchowych. Miały one jednak najczęściej postać beztroskich zabaw konwencjonalnymi przyborami (piłkami, patyczkami, woreczkami, na sankach).

\section{Literatura}

Beith K., Robinson M., Pullan L., 2003, Early Years care and Education. Heinemann Educational Publishers, Oxford, s. 124.

Bell J., 1995, Doing your research project, Open University Press, Buckingham.

Bizley K., 1996, Examining Physical Education, Heinemann Educational Publishers, Oxford, s. 14-15.

Boyarsky T., 2011, Using Music and Movement to Develop Character and Illustrate Conflict Resolution, (w:) J. Dowdy, S. Kaplan (eds.), Teaching Drama in the Classroom. A Toolbox for Teacher, Sense Publishers, Rotterdam, s. 63-67.

Bunker D., 1994, Games, (w:) D. Bunker, C. Hardy, B. Smith, L. Almond (eds.), Primary Physical Education: Implementing the National Curriculum, Cambridge University Press, Cambridge, s. 89-126. 
Corbin Ch., Lindsey R., 1997, Concepts of Physical Fitness, Brown \& Benchmark, Chicago.

Cuttance P., 1996, Evaluating the Effectiveness of Schools, (w:) D. Reynolds, P. Cuttance (eds.), Schools Effectiveness. Research, policy and practice, Redwood Books, London, s. 71-96.

De Vaus D., 1996, Surveys in Social Research, University College, London, s. 6-7.

Flick U., 2011, Jakość w badaniach jakościowych, PWN, Warszawa, s. 14.

Gallahue D., Cleland-Donnelly F., 2007, Developmental Physical Education for All Children, Champaigne, s. 14.

Gnitecki J., 1996a, Elementy metodologii badań w pedagogice hermeneutycznej, Wyższa Szkoła Pedagogiczna, Zielona Góra, s. 22-23.

Gnitecki J., 1996b, Metodologiczne problemy pedagogiki prakseologicznej, Wyższa Szkoła Pedagogiczna, Zielona Góra.

Gołębiowski Ł., 1831, Zabawy różnych stanów w kraju całym, lub niektórych tylko prowincjach. Umieszczony tu: kulig, czyli szlichtada, zapusty, łowy, maszkary, muzyka, tańce, reduty, ognie sztuczne, rusałki, sobótki itp., Nakładem autora, Warszawa.

Goodwin W., Goodwin L., 1996, Understanding Quantitative and Qualitative Research in Early Childhood Education, Columbia University, New York, s. 170-172.

Góralski A., 1987, Metody opisu i wnioskowania statystycznego w psychologii i pedagogice, PWN, Warszawa, s. 136.

Hammerling W., 1985, Zabawy w nauczaniu początkowym, Wydawnictwa Szkolne i Pedagogiczne, Warszawa, s. 11-12.

Hemerling K., 1907, O znaczeniu i potrzebie zabaw ruchowych w wychowaniu, Księgarnia Polska, Lwów, s. 3.

Huizinga J., 1985 (1938), Homo ludens. Zabawa jako źródło kultury, Czytelnik, Warszawa.

Kist W., 2011, Virtual Role-Playing, (w:) J. Dowdy, S. Kaplan (eds.), Teaching Drama in the Classroom. A Toolbox for Teacher, Sense Publishers, Rotterdam, s. 37-40.

Kmita J., 1971, Z metodologicznych problemów interpretacji humanistycznej, PWN, Warszawa, s. 7-38.

Kozłowski K., 1869, Gry i zabawy dla młodzieży, Decker i spółka, Poznań.

Leech N., Onwuegbuzie A., 2009, A typology of mixed methods research designs, „Quality \& Quantity", vol. 43, Issue 2, s. 265-275.

Lenel R., 1984, Games in the Primary School, Hodder \& Stoughton, Middlesex.

Łobocki M., 2003, Metody i techniki badań pedagogicznych, Wydawnictwo Impuls, Kraków.

Macdonald K., Tipton C., 1996, Using documents, (w:) N. Gilbert (ed.), Researching social life, SAGE Publications, London, s. 191-192.

Matwijów B., 1998, Budowanie teoretycznej wiedzy pedagogicznej, (w:) S. Palka (red.), Orientacje w metodologii badań pedagogicznych, Kraków, s. 15-24.

McNeill P., 1986, Research Methods, Tavistock Publications, London, s. 87.

Molesztak A., 1994, Zadania wychowawcze w rozważaniach teorii wychowania, (w:) A. Tchorzewski (red.), Z problematyki metodologicznej teorii wychowania, Wyższa Szkoła Pedagogiczna, Bydgoszcz, s. 63-67.

Nowak-Łojewska A., 2004, Zintegrowane zadania w edukacji wczesnoszkolnej, Wydawnictwo Akademickie Żak, Kraków.

Palka S., 2006, Metodologia. Badania. Praktyka pedagogiczna, Gdańskie Wydawnictwo Psychologiczne, Gdańsk, s. 30, 42.

Pieter J., 1967, Ogólna metodologia pracy naukowej, Ossolineum, Wrocław, s. 108.

Pilch T., Bauman T., 2001, Zasady badań pedagogicznych, Strategie ilościowe i jakościowe, Wydawnictwo Akademickie „Żak”, Warszawa, s. 36-37, 297-300.

Potter R., 2004, An Introduction to children's learning, (w:) K. Jacques, R. Hyland (eds.), Professional Studies. Primary Phase, Learning Matters, Exeter, s. 63-73.

Reid K., Hopkins D., Holly P., 1990, Toward the Effective School. The problems and some solutions, Basil Blackwell, Oxford Publishing Services, Oxford, s. 115-136.

Schutz P., Chambless C., DeCuir J., 2008, Multimethods Research, (w:) K. deMarrais, S. Lapan (eds.), Methods of Inquiry and the Social Sciences, Taylor \& Francis Routledge, New York, s. 267-282.

Silverman D., 2007, Interpretacja danych jakościowych, PWN, Warszawa, s. 145-182. 
Spencer L., Ritchie J., Lewis J., Dillon L., 2003, Quality in Qualitative Evaluation. A framework for assessing research evidence, Cabinet Office, London, s. 53.

Urbaniak-Zając D., 2013, Obiektywna hermeneutyka jako metodologia i metoda badań empirycznych, (w:) D. Urbaniak-Zając, E. Kos, Badania jakościowe w pedagogice, PWN, Warszawa, s. 169-221.

Waloszek D., 1993, Rola zadań w wychowaniu dzieci w wieku przedszkolnym, Ośrodek Doskonalenia Nauczycieli, Zielona Góra, s. 14-15.

Walter G., 1999, Spielen und lernen in Kindergarten und Familie, Velber, Seelze.

Więckowski R., 1998, Pedagogika wczesnoszkolna, Wydawnictwa Szkolne i Pedagogiczne, Warszawa, s. 35.

Winczewski P., 2014a, Zróżnicowanie aktywności zawodowej kobiet i mężczyzn w fabułach zabaw ruchowych, (w:) W. Welskop (red.), Przyszłość edukacji - edukacja przyszłości, Wyższa Szkoła Biznesu i Nauk o Zdrowiu, Łódź, s. 123-130.

Winczewski P., 2014b, Zróżnicowanie fabuł zabaw muzyczno-ruchowych, „Konteksty Kształcenia Muzycznego", 1 (1). s. 53-67.

Winczewski P., 2015, Zróżnicowanie wątków fabularnych dydaktycznych zabaw ruchowych, (w:) J. Bujak-Lechowicz (red.), Kulturowy obraz rozrywki, Volumina, Szczecin, s. 349-362.

Woynarowska B., 2012, Status i miejsce edukacji zdrowotnej w podstawie programowej kształcenia ogólnego, (w:) B. Woynarowska (red.), Organizacja i realizacja edukacji zdrowotnej w szkole. Poradnik dla dyrektorów i nauczycieli gimnazjum, Ośrodek Rozwoju Edukacji, Warszawa, s. 19-23.

Wroczyński R., 1985, Powszechne dzieje wychowania fizycznego i sportu, Ossolineum, Wrocław, s. 92-95.

Zbiór rozmaitych zabaw w posiedzeniach czyli sztuka bawienia się we wszystkich porach roku tak na wolnem powietrzu, jako też w domu zawierająca naylepsze gry, śpiewy, wiersze, powieści, zagadki i różne sztuki dla wesołych familii, 1821, Wilhelm Bogumił Korn, Wrocław.

Żechowska B., 1985, Wybrane metodologiczne wzory badań empirycznych w pedagogice, Uniwersytet Śląski, Katowice, s. 55, 63-67. 